approximately $4 \mathrm{~min}$. Phase 1 lasted for 7 days or a total of 140 trials.

In Phase 2, barrier distances of 15 and $20 \mathrm{in}$. were used to provide a more difficult discrimination. Phase 2 lasted for 5 days or a total of 100 trials.

As a final test that $S$ s were still responding to distance cues, Phase 3 consisted of 1 day of 20 trials with the original discrimination distances of $11 \frac{1}{2}$ and 23 in.

Results and Conclusions

Results of Experiment 2 are presented in Fig. 3. Clearly, all Ss learned to discriminate distance in order to obtain food reinforcement. Since no reliable differences were found with respect to the long vs short arm, all Ss were combined for data analysis. By the final block of Phase 1 , Ss were making the correct choice with $98 \%$ accuracy. When the discrimination was made more difficult in Phase 2, performance immediately dropped to approximately $75 \%$ accuracy and did not improve over a 5-day period. In Phase 3, Ss were returned to the initial discrimination of Phase 1 and the result was an immediate return to $97 \%$ accuracy. From this experiment, it was concluded that gerbils do have distance perception, at least within the ranges used in the present experiment. Nearly perfect discrimination was possible when the arms differed by $11 \frac{1 / 2}{2}$ in. and $75 \%$ accuracy was maintained when the difference was only 5 in.

\section{REFERENCES}

BOICE, $R$, BOICE, C. \& DUNHAM, A. E. Role of docility in avoidance: Gerbils and kangaroo rats in a shuttlebox. Psychonomic Science, 1968, 10, 381-382.

NAUMAN, D. J. The Mongolian gerbil as an experimental animal in behavioral research. Paper read at North and South Dakota Bi-State Psychological Convention, South Dakota, 1963.

NAUMAN, D. J. Open field behavior of the Mongolian gerbil. Psychonomic Science, 1968, $10,163-164$.

THIESSEN, D. D. The roots of territorial marking in the Mongolian gerbil: A problem of species-common to pography. Behavio Research Methods \& Instrumentation, 1968, 1 , 70-76.

THIESSEN, D. D., LINDZEY, G., BLUM, S. TUCKER, A., \& FRIEND, H. Visual behavior of the Mongolian gerbil (Meriones unguiculatus). Psychonomic Science, 1968, 11, 23-24.

WALTERS, G. C., PEARL, J., \& ROGERS, J. V. The gerbil as a subject in behavioral research. Psychological Reports, 1963, 12, 315-318.

\section{NOTES}

1. Cole, J. M., \& Topping, J. S. Twenty-four hour activity cycles in the Mongolian gerbil. Unpublished manuscript, 1969.

\title{
Enhanced pattern discrimination learning following unilateral damage to posterior cortex in rats
}

\begin{abstract}
THOMAS J. BOLES, University of Utah and Veterans Administration Hospital, Salt Lake City, Utah 84112, and CHARLES L. SHERIDAN, University of Missouri and Veterans Administration Hospital, Kansas City, Mo. 64110
\end{abstract}

Rats with unilateral damage to the posterior cortex, including the "visual" cortex, learned a monocular pattern discrimination substantially more quickly than did an unoperated group. A unilaterally blinded group did not differ reliably from unoperated animals.

In several experiments, groups of albino rats with unilateral ablation of the "visual" cortex have acquired a monocular pattern discrimination more rapidly than unoperated or "sham" operated groups (Creel \& Sheridan, 1965; Dunsmore, Creel, $\&$ Sheridan, 1965). It is easy to account for these findings by postulating the presence of interhemispheric interference in intact animals. Indeed, there have been several studies reported in the literature which are very much in consonance with the view that across-the-midline interference occurs. Krech, Rosenzweig, \& Bennett (1960) found that unilateral lesions in the visual and somesthetic cortex of rats causes a "slight but significant" increase in cholinesterase activity in the contralateral cortex. Bingelli, Tschirgi, \& Wenzel (1963) found that unilateral tectal lesions augmented the learning of visual discriminations in pigeons. Sprague (1966) has shown that a reciprocally interfering relationship holds between the two superior colliculi in cats under some circumstances. All of these phenomena are intelligible if across-the-midline interference of symmetrical brain halves is postulated.

It would be of considerable interest if such mutual interference of the two cerebral hemispheres in rats could be shown to occur, but the evidence is only suggestive, and the replicability of these findings as well as their susceptibility to alternative interpretations need to be evaluated. It was with the latter two needs in mind that the present experiment was undertaken. Our first purpose was to replicate the previous findings of enhanced discrimination learning following unilateral ablation. Our second purpose was to evaluate a simple hypothesis which suggests itself as an alternative to the above mentioned central interference hypothesis. If an important component of the monocular discrimination task has to do with the acquisition of orientations appropriate to the unilaterally blinded condition, operated (and therefore hemianopic) rats might come to the task from an advantageous starting point.

Operated animals can presumably learn new habits of visual fixation in the home cage, whereas unoperated animals must acquire them while learning the discrimination task. The experiment reported here made possible the evaluation of this "visual fixation" hypothesis by determining whether unilateral orbital enucleation has an effect equivalent to that of unilateral striate ablation.

\section{SUBJECTS}

Twenty-one male Sprague-Dawley albino rats obtained from Simonsen Laboratories, Inc., Day Road, Gilroy, California, were used as Ss.

\section{APPARATUS}

Training was given in a Thompson-Bryant apparatus (Thompson \& Bryant, 1955), which utilized shock motivation and consisted of a start box, runway, choice point with two alternative entryways (blocked by the cue doors), and a goalbox.

\section{PROCEDURE}

From the original pool of 21 rats, seven pairs were selected haphazardly for surgery. The members of each pair were anesthetized with Nembutal ( $50 \mathrm{mg} / \mathrm{kg}$, intraperitoneal) and then one of them was chosen at random for striate ablation, the other for removal of one eye. Ablations were accomplished by subpial aspiration. Enucleations were done by introducing a forceps underneath the orb and cutting it away with scissors.

After at least 2 weeks of recovery, Ss were selected from the pool of 21 rats to be run in squads, usually of four animals. Each squad included at least one animal from each of the three treatment groups.

Subjects were pretrained to run to the goalbox, and to knock over grey cue cards which blocked the goalbox entryways. One eye was then covered with an opaque contact occluder similar to those of Schuck \& Copolla (1963), except that it covered the eye to its base, and Ss were trained to discriminate $1 / 2$-in. horizontal from $1 / 2$-in. vertical stripes which were taped to the cue doors. The correct cue was varied unsystematically across Ss. Right-left position of the correct stimulus was determined by a Gellerman series (Gellerman, 1933). Training continued until a criterion of 18 correct responses in 20 consecutive trials was met.

After completion of the experiment, the ablated rats were sacrificed by perfusion in mammalian Ringer's solution followed by $10 \%$ formalin. Their brains were removed, embedded in paraffin; and 10-micron coronal sections were taken over varying 
Table 1

Median Trials and Errors to Two Leaming Criteria for Unoperated, Enucleated, and Ablated Groups

\begin{tabular}{lccccc} 
& \multicolumn{2}{c}{9 Correct in 10 Trials } & \multicolumn{2}{c}{18 Correct in 20 Trials } \\
\cline { 2 - 5 } & Trials & Errors & Trials & Errors \\
\hline Unoperated & 65.0 & 35.0 & 78.0 & 35.0 \\
Enucleated & 59.5 & 31.5 & 66.5 & 32.5 \\
Ablated & 37.0 & 22.0 & 48.0 & 22.0 \\
\hline
\end{tabular}

Table 2

Median Trials and Errors to Two Learning Criteria for Enucleated and Ablated Groups Expressed as a Percentage of Median Trials for Unoperated Group on Same Measure. ( $P$ values result from Mann-Whitney $U$ tests comparing group with unoperated animals.)

\begin{tabular}{|c|c|c|c|c|}
\hline & \multicolumn{2}{|c|}{9 Correct in 10 Trials } & \multicolumn{2}{|c|}{18 Correct in 20 Trials } \\
\hline & Trials & Errors & Trials & Errors \\
\hline Enucleated & $\begin{array}{l}91.5 \\
\text { (all p's }\end{array}$ & $\begin{array}{c}90.0 \\
\text { han .2) }\end{array}$ & 88.1 & 92.0 \\
\hline Ablated & $\begin{array}{l}56.9 \\
\text { (all p's }\end{array}$ & $\begin{array}{l}62.8 \\
.02)\end{array}$ & 62.2 & 62.9 \\
\hline
\end{tabular}

extents of the brains, always including a number of sections through the dorsal lateral geniculate nuclei. The brains were examined with particular attention bein given to the extent of degeneration in the dorsal lateral geniculate body ipsilateral to inc: Lesion. A few healthy cells could be seen in the ipsilateral lateral geniculate of virtually every $S$. In most cases, the proportion of surviving cells was estimated at about $1 \%$. No animal had more than an estimated $20-25 \%$ of cells surviving. Lesions were generally deep, hippocampus having been damaged in most Ss. The operated hemisphere of one animal was almost completely degenerated.

\section{RESULTS}

One $S$ was lost from the enucleated group due to $\mathrm{E}$ error. Median numbers of trials and errors to a criterion of 9 correct responses in 10 consecutive trials, and to a criterion of 18 correct responses in 20 consecutive trials, are given for each group in Table 1.

Note that, for each of the four measures, differences between unoperated and enucleated groups are small. Ablated animals, on the other hand, acquired the discrimination with substantially greater facility than unoperated animals. Table 2 expresses median trials and errors to criteria for the two operated groups as a percentage of the corresponding measures for the unoperated group.

Enucleated animals required about $90 \%$ and ablated animals only about $60-65 \%$ as many trials as the unoperated group. Two-tailed Mann-Whitney U tests were used to compare the unoperated group to each of the two experimental groups on each of the four measures. The probabilities stemming from these tests are given in parentheses beneath the percentages in Table 2 . The enucleated group $p$ values did not approach customarily accepted levels of confidence, whereas the operated group p's were less

Since the slowest learner among the ablated animals also had the most extensive lesion, the relationship between lesion size and trials to the $18 / 20$ criterion was evaluated for the ablated group. A Kendall tau was computed to find the correlation between rank on the lesion size variable and rank on the trials to criterion variable. The correlation was statistically significant $(\operatorname{tau}=.87, \mathrm{p}<.05)$

\section{DISCUSSION}

It would seem that the ability of the albino rat to learn a pattern discrimination the posterior cortex, and that this enhancement is not simply a function of adjustments to hemianopia. The present data therefore contribute one more item of evidence consistent with the hypothesis that there is across-the-midline interference of symmetrical brain halves. However, there still remain certain barriers to our enthusiastic espousal of this hypothesis. The most important of these is that too little is known of the conditions under which enhancement will or will not occur. Though, with the present study, there have now been three consecutive experiments in which rats with unilateral striate ablations learned more quickly than controls, the effect is sometimes a weak one, and the basis for variations in its strength is not understood. Since there was a positive correlation between lesion size and trials taken to learn, it would appear that, in order to maximize the effects, lesions should be kept small and an effort should probably be made to restrict them to the striate region. But it remains to be seen whether this procedure will increase the uniformity of experimental outcomes in any substantial way. The effect of other variables such as type of than .02 for each of the four measures. is, indeed, enhanced by unilateral damage to discrimination, type of motivation, etc., is simply not known. The "interference" interpretation of these findings cannot be taken as more than a plausible hypothesis until a thorough profile of the variables controlling the phenomena has been amassed.

The present findings are strikingly in consonance with those of Bingelli, Tschirgi, \& Wenzel (1963). They found that unilateral tectal lesions augmented the learning of visual discriminations in pigeons and that, as in the present experiment, animals with damage to the eye learned at rates comparable to those of unoperated animals. They also found that enhanced learning did not occur in Ss with lesions going beyond the tectum. This may be related to the present findings of a positive correlation between lesion size and trials taken to learn, since Ss with larger lesions undoubtedly tended to suffer greater degrees of extra-striate damage. The similarity between the rat and pigeon findings seems to indicate a phylogenetically widespread phenomenon. But again, circumspection must be used until both sets of phenomena have been described more fully.

\section{REFERENCES}

CREEL, D. J., \& SHERIDAN, C. L. Monocular acquisition and interocular transfer in albino rats with unilateral striate ablations. Psychonomic Science, 1966, 6, 89-90.

BINGELLI, R. L., TSCHIRGI, R. D., \& WENZEL, B. M. Effects of unilateral hemispheric and optic tectal ablations on visual discrimination learning in pigeons. The Physiologist, 1963, 6, 140 (abstract).

DUNSMORE, N. M., CREEL, D. J., \& SHERIDAN, C. L. Enhanced discrimination learning in hemidecorticated rats. Paper read at annual meeting of Midwestern Psychological Association, 1965.

GELLERMAN, L. W. Chance orders of alternating stimuli in visual discrimination experiments. Journal of Genetic Psychology, 1933, 42, 206-208.

KRECH, D., ROSENZWEIG, M. R., \& BENNETT, E. L. Interhemispheric effects of cortical lesions on brain biochemistry. Science, 1960,132 , 352-353.

SHUCK, J. R., \& COPPOLA, L. A. Contact occluders for restricting vision in the rat. American Journal of Psychology, 1963, 76, 135-137.

THOMPSON, R., \& BRYANT, H. Memory as affected by activity of the relevant receptor. Psychological Reports, 1955, 1, 303-400.

NOTE

1. Supported in part by funds from Public Health Service Grant MH 12268 to Charles L. Sheridan and in part by 8200 funds from the U.S.V.A. Hospital Neuropsychology Laboratories. Reprint requests should be sent to C. L. Sheridan, Department of Psychology, University of Missouri, Kansas City, Mo.64110. 